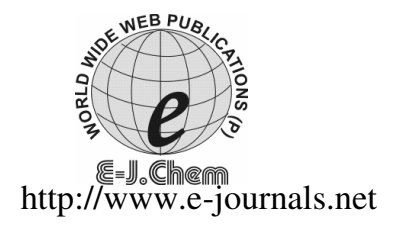

ISSN: 0973-4945; CODEN ECJHAO

E-Journal of Chemistry

$2011, \mathbf{8}(2), 587-593$

\title{
Third Derivative Spectrophotometric Method for Simultaneous Determination of Copper and Nickel Using 6-(2-Naphthyl)-2, 3-dihydro-1,2,4- triazine-3-thione
}

\author{
MALIHEH BARAZANDEH TEHRANI and EFFAT SOURI
}

\author{
Department of Medicinal Chemistry \\ Faculty of Pharmacy and Pharmaceutical Sciences Research Center \\ Tehran University of Medical Sciences, Tehran, Iran \\ barazand@tums.ac.ir
}

Received 6 July 2010; Accepted 3 September 2010

\begin{abstract}
A simple and sensitive derivative spectrophotometric method for simultaneous determination of nickel and copper using 6-(2- naphthyl)-2,3dihydro-1,2,4-triazine-3-thione (NDTT) as a selective analytical reagent was developed. The complexes of metal ions with NDTT were formed immediately in basic media and extracted with chloroform. The zero-crossing measurement technique was found suitable for the direct measurement of the third-derivative value of Ni-NDTT and Cu-NDTT at 501 and $472 \mathrm{~nm}$ respectively. Beer's law is obeyed in the concentration range $1-30 \mu \mathrm{g} / \mathrm{mL}$ for both cations with different ratios. The limit of detection was $0.26 \mu \mathrm{g} / \mathrm{mL}$ and $0.13 \mu \mathrm{g} / \mathrm{mL}$ for copper and nickel respectively. The within day and between day variations showed coefficient of variation (CV\%) values less than 2.80 and 2.97 for copper and nickel respectively. The error of the determination method did not exceed $6.50 \%$. Analysis of alloy sample showed that this method can be successfully used for simultaneous determination of $\mathrm{Cu}$ and $\mathrm{Ni}$ in real samples.
\end{abstract}

Keywords: Derivative spectrophotometry, Simultaneous determination, Nickel, Copper

\section{Introduction}

$\mathrm{Cu}(\mathrm{II})$ and $\mathrm{Ni}(\mathrm{II})$ are metal ions which appear together in a wide variety of samples (environmental, industrial, geometrical and pharmaceutical). This point indicates a potential interest in simultaneous determination of these metal ions. Various spectrophotometric and extraction methods based on different ligands has been described for determination of copper or nickel individually ${ }^{1-3}$. Many of these methods are time consuming or require complicated and expensive instruments. A few works have been reported for simultaneous determination of these ions ${ }^{4}$. 
Spectrophotometric methods are industrial method of choice commonly used in laboratories because of their simplicity, selectivity and sensitivity. It needs less expensive instrumentation and provides high sensitivity when appropriate chromogenic reagents are available . $^{5-6}$

Derivative spectrophotometry has been shown to be a powerful tool for quantitative analysis of multi-component mixtures. It leads, not only to an increase in selectivity, but also in many cases, to an increase in sensitivity ${ }^{7-9}$. It is also of great utility to resolve overlapping spectra, particularly for binary mixtures.

The zero-crossing method has been applied successfully for the simultaneous determination of metal ions in their binary mixtures through the formation of complexes with some organic ligands ${ }^{10-11}$. There may be some difficulties in determining trace amount of metal ions due to matrix interferences. Consequently, using a more specific ligand is usually required. 6-(2-Naphthyl)-2,3-dihydro-1,2,4-triazine-3-thione (NDTT) (Figure 1) was recently synthesized in our laboratory as a new reagent for determination of $\mathrm{Cu}$. This reagent forms colored complex with a few metals ${ }^{12}$. Its red complex with $\mathrm{Cu}$ is easily extractable with chloroform in basic condition. It is also used for determination of $\mathrm{Cu}$ in human serum ${ }^{13}$.

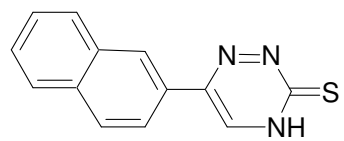

Figure 1. Chemical structure of 6-(2-naphtyl)-2, 3-dihydro-1,2,4-triazine -3-thione (NDTT)

In this study, derivative spectrophotometric method is proposed for simultaneous determination of $\mathrm{Cu}(\mathrm{II})$ and $\mathrm{Ni}(\mathrm{II})$ based on the reaction between the ions and recently synthesized chromogenic compound (NDTT). Various factors such as wavelength effect of foreign ions and ranges of applicability of Beer's law were also studied.

\section{Experimental}

Absorbance measurements were carried out by means of a Shimadzu 160A (Japan) UV-VIS spectrophotometer.

\section{Chemicals}

The reagent, 6-(2-naphtyl)-2, 3, dihydro-1,2,4-triazine-3-thione (NDTT) was synthesized based on reaction of 2-acethylnaphthalene with amyl nitrite under anhydrous conditions. It produced 2-naphthyl glyoxaldoxime which upon reaction with thiosemicarbazide yielded 6-(2-naphthyl)-2, 3- dihydro-1,2,4-triazine-3-thione ${ }^{12}$. Chloroform, sodium hydroxide and tartaric acid were of analytical grade and prepared from Merck (Darmstadt, Germany).

\section{Reagent solutions}

NDTT solution $(0.0032 \mathrm{M})$ was prepared by dissolving accurately weighed of pure reagent in sodium hydroxide (1 M). It should be freshly prepared before use.

\section{Standard solutions}

\section{Copper nitrate solution}

Pure elemental copper (exactly $0.500 \mathrm{~g}$ ) was dissolved in hot concentrated $\mathrm{HNO}_{3}$. After cooling, $50 \mathrm{~mL} \mathrm{HNO}_{3}(1: 1)$ was added and the volume was adjusted to $500 \mathrm{~mL}$ by addition of distilled water to reach a final concentration of $1 \mathrm{mg} / \mathrm{mL}$.

\section{Nickel nitrate solution}

Nickel nitrate solution was also prepared by the above mentioned method for copper nitrate solution. The final concentration was reached to $1 \mathrm{mg} / \mathrm{mL}$. 


\section{Calibration solutions}

Stock standard solutions of copper nitrate and nickel nitrate was prepared by diluting the standard solutions $(1 \mathrm{mg} / \mathrm{mL})$ to a final concentration of $100 \mu \mathrm{g} / \mathrm{mL}$. Different amounts of the stock standard solutions were transferred into two series of $100 \mathrm{~mL}$ calibrated flasks. The first series contained a constant quantity of copper $(10 \mu \mathrm{g} / \mathrm{mL})$ and varying concentrations of nickel $(1,2,5,10,25$ and $30 \mu \mathrm{g} / \mathrm{mL})$. The second series contained a constant concentration of nickel $(10 \mu \mathrm{g} / \mathrm{mL})$ and varying concentrations of copper $(1,2,5,10,25$ aand $30 \mu \mathrm{g} / \mathrm{mL})$.

\section{General procedure}

A mixture of $1 \mathrm{~mL}$ of standard solutions of $\mathrm{Cu}^{2+}$ and $\mathrm{Ni}^{2+}, 1 \mathrm{~mL}$ of NDTT solution $(0.0032 \mathrm{M}$ in $1 \mathrm{M} \mathrm{NaOH}$ ), $1 \mathrm{~mL}$ tartaric acid $2 \mathrm{M}$ and $1 \mathrm{~mL}$ sodium hydroxide $1 \mathrm{M}$ was mixed thoroughly in a $100 \mathrm{~mL}$ separatory funnel and the resulting colored complex was extracted 2 times with $5 \mathrm{~mL}$ of chloroform. The chloroform layer was dried by addition of anhydrous sodium sulfate. The extracts were collected in a $10 \mathrm{~mL}$ volumetric flask and adjusted to the volume with chloroform.

\section{Spectrophotometric measurements}

Zero-order spectra of standard solutions of copper $(20 \mu \mathrm{g} / \mathrm{mL})$ and nickel $(20 \mu \mathrm{g} / \mathrm{mL})$ complexes with NDTT versus their reagent blanks were recorded in the range of 200-600 $\mathrm{nm}$. The thirdorder derivative spectra of standard solutions of each metal complex with NDTT were obtained in the range of 250-600 nm against their blanks. The values of $\mathrm{D}_{3}$ amplitudes for copper complex in the presence of nickel and vice versa were measured at $472 \mathrm{~nm}$ (zero-crossing point of nickel complex) and $501 \mathrm{~nm}$ (zero-crossing point of copper complex) respectively.

\section{Linearity}

Calibration curves were constructed using six series of standard copper solutions $(1,2,5,10$, 25 and $30 \mu \mathrm{g} / \mathrm{mL})$ in the presence of nickel $(10 \mu \mathrm{g} / \mathrm{mL})$. The same procedure was used for solutions contained nickel $(1,2,5,10,25$ and $30 \mu \mathrm{g} / \mathrm{mL})$ in the presence of copper $(10 \mu \mathrm{g} / \mathrm{mL})$. The calibration curves were constructed and statistical analysis was performed.

\section{Accuracy and precision}

To establish the reliability of the proposed method, two series of solutions containing 1,10 and $30 \mu \mathrm{g} / \mathrm{mL}$ of copper solution and $10 \mu \mathrm{g} / \mathrm{mL}$ nickel and 1,10 and $30 \mu \mathrm{g} / \mathrm{mL}$ of nickel plus $10 \mu \mathrm{g} / \mathrm{mL}$ copper were prepared and analyzed using described method. To evaluate repeatability of the method three series of these synthetic mixtures were assessed in one day using their corresponding calibration curves. Mixtures of similar concentrations were analyzed on three different days to obtain reproducibility. To obtain the accuracy of the method the percentage of deviation between added amounts and measured concentrations of the above solutions was calculated.

\section{Interference analysis}

A standard solution containing $10 \mu \mathrm{g}$ of $\mathrm{Cu}^{2+}$ and $10 \mu \mathrm{g} \mathrm{Ni}^{2+}$ and possible interfering ions were transferred to a separately funnel. The method was completed according to the general procedure to find out any interference from other ions.

\section{Analysis of alloy samples}

About $0.1 \mathrm{~g}$ sample mass taken from constantan alloy was solubilized in hot concentrated $\mathrm{HNO}_{3}$. After cooling, $20 \mathrm{~mL} \mathrm{HNO}_{3}$ (1:1) was added. The solutions were diluted with appropriate amount of deionized water and the volume was adjusted to $100 \mathrm{~mL}$. 


\section{Results and Discussion}

\section{Absorption spectra}

It was found that NDTT reacts with copper and nickel ions to form stable red and yellow complexes in basic medium. Optimum reaction condition was reported previously ${ }^{12}$. Zeroorder absorption spectra of these complexes showed overlapping (Figure 1) which makes the direct simultaneous determination very difficult.

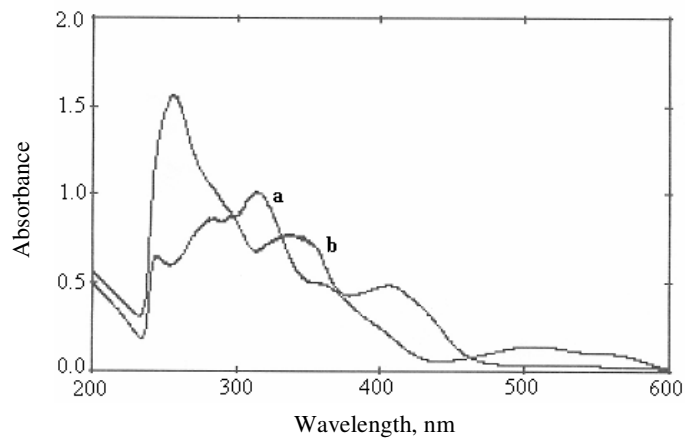

Figure 1. Zero-order spectra of (a) Cu-NDTT complex and (b) Ni-NDTT complex

Derivative spectrophotometry, based on a mathematical transformation of the zeroorder curve into the derivative spectra can overcome this problem ${ }^{14-16}$. In this investigation appropriate parameters were selected to record the third-derivative spectra to obtain suitable wavelength for determination. The third-order derivative spectra traced with $\Delta \lambda=5.6(\mathrm{n}=8)$ was used to resolve the spectral overlapping (Figure 2). Zero-crossing points of Cu-NDTT $(501 \mathrm{~nm})$ and Ni-NDTT $(472 \mathrm{~nm})$ were used for simultaneous determination of copper and nickel ions.

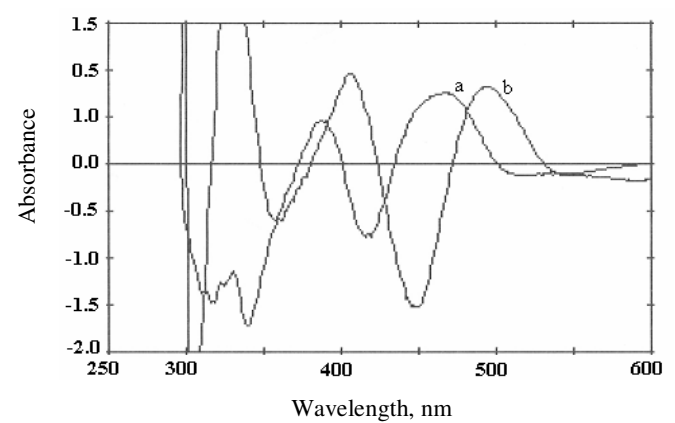

Figure 2. Third-order derivative spectra of (a) Cu-NDTT complex and (b) Ni-NDDT complex

\section{Calibration curve and statistical analysis}

The linearity of the present method was established from the third-derivative spectra by measuring the absorbance of standard solutions $(n=9)$ containing the various concentrations of each compound with the constant concentration of the other one. The calibration curves were constructed by plotting the $\mathrm{D}_{3}$ values against copper or nickel concentration at the zero-crossing wavelength of nickel-NDTT $(472 \mathrm{~nm})$ or copper-NDTT $(501 \mathrm{~nm})$. The results are summarized in Table 1. The linearity of the calibration curves and the adherence of the method to Beer's law are validated by the high value of the correlation coefficient. 
Table 1. Statistical data of calibration curves of Cu-NDTT and Ni-NDTT in mixtures with different concentrations using third derivative spectra.

\begin{tabular}{lcc}
\hline Parameters & Copper & Nickel \\
\hline Linearity & $1-30 \mu \mathrm{g} / \mathrm{mL}$ & $1-30 \mu \mathrm{g} / \mathrm{mL}$ \\
Regression equation & $\mathrm{Y}=0.0314 \mathrm{x}-0.0054$ & $\mathrm{Y}=0.0236 \mathrm{x}+0.0029$ \\
SD of slope & $2.14 \times 10^{-4}$ & $5.5 \times 10^{-5}$ \\
RSD of slope & 0.68 & 0.23 \\
SD of intercept & $1.2 \times 10^{-2}$ & $4.2 \times 10^{-3}$ \\
Correlation coefficient & 0.9999 & 0.9998 \\
\hline
\end{tabular}

\section{Sensitivity}

The limit of quantification with $\mathrm{CV}<2.97 \%$ was found to be $1 \mu \mathrm{g} / \mathrm{mL}$ both for copper and nickel ions. The limit of detection that can be reliably detected with a signal to noise ratio of 3 was found to be $0.26 \mu \mathrm{g} / \mathrm{mL}$ and $0.13 \mu \mathrm{g} / \mathrm{mL}$ for copper and nickel respectively.

\section{Accuracy and precision}

The accuracy and precision were determined by using synthetic mixtures of copper and nickel. The mean recoveries and CV values are illustrated in Tables 2 and 3. Data of these tables showed good accuracy and precision over the concentration range. The within-day and between-day variations showed coefficient of variation (CV\%) values less than 2.80 and 2.97 for copper and nickel respectively in all three selected concentrations. These data indicate that the proposed derivative spectrophotometric method is highly precise during one run and between different runs.

Table 2. Accuracy and precision data of determination of copper $(1-30 \mu \mathrm{g} / \mathrm{mL})$ in the presence of nickel $(10 \mu \mathrm{g} / \mathrm{mL})$ by third- derivative spectrophotometry.

\begin{tabular}{ccccccc}
\hline \multirow{2}{*}{$\begin{array}{c}\text { Added, } \\
\mu \mathrm{g} / \mathrm{mL}\end{array}$} & \multicolumn{3}{c}{ Within-day $(\mathrm{n}=3)$} & \multicolumn{3}{c}{ Between-day $(\mathrm{n}=9)$} \\
\cline { 2 - 7 } & $\mu \mathrm{g} / \mathrm{mL}$ & $\mathrm{CV}$, & $\begin{array}{c}\text { Error, } \\
\%\end{array}$ & $\begin{array}{c}\text { Found } \\
\mu \mathrm{g} / \mathrm{mL}\end{array}$ & $\begin{array}{c}\mathrm{CV}, \\
\%\end{array}$ & $\begin{array}{c}\text { Error, } \\
\%\end{array}$ \\
\hline 1 & $1.06 \pm 0.02$ & 1.89 & 6.00 & $1.07 \pm 0.03$ & 2.80 & 6.50 \\
10 & $9.79 \pm 0.08$ & 0.82 & 2.10 & $9.92 \pm 0.17$ & 1.71 & 0.80 \\
30 & $30.01 \pm 0.09$ & 0.30 & 0.03 & $29.99 \pm 0.14$ & 0.47 & 0.03 \\
\hline
\end{tabular}

Table 3. Accuracy and precision data of determination of nickel $(1-30 \mu \mathrm{g} / \mathrm{mL})$ in the presence of copper $(10 \mu \mathrm{g} / \mathrm{mL})$ by third- derivative spectrophotometry.

\begin{tabular}{ccccccc}
\hline \multirow{2}{*}{$\begin{array}{c}\text { Added, } \\
\mu \mathrm{g} / \mathrm{mL}\end{array}$} & \multicolumn{3}{c}{ Within-day $(\mathrm{n}=3)$} & \multicolumn{3}{c}{ Between-day $(\mathrm{n}=9)$} \\
\cline { 2 - 7 } & $\begin{array}{c}\text { Found, } \\
\mu \mathrm{g} / \mathrm{mL}\end{array}$ & $\mathrm{CV}$, & Error, & Found, & $\mathrm{CV}$, & Error, \\
& $0.999 \pm 0.01$ & 1.00 & 0.01 & $1.01 \pm 0.03$ & 2.97 & 1.00 \\
1 & $9.87 \pm 0.06$ & 0.61 & 0.9 & $9.87 \pm 0.21$ & 2.13 & 1.30 \\
10 & $30.013 \pm 0.24$ & 0.80 & 0.43 & $29.97 \pm 0.18$ & 0.60 & 0.10 \\
\hline
\end{tabular}

\section{Interference analysis}

The effect of foreign ions on determination of $10 \mu \mathrm{g}$ of $\mathrm{Cu}^{2+}$ and $10 \mu \mathrm{g}$ of $\mathrm{Ni}^{2+}$ was studied using the general procedure. Among the interfering ions tested, $\mathrm{Mn}^{2+}, \mathrm{Bi}_{3}{ }^{+}$, $\mathrm{Cr}_{2} \mathrm{O}_{7}{ }^{2-}, \mathrm{Br}^{-}, \mathrm{CH}_{3} \mathrm{COO}^{-}, \mathrm{K}^{+}, \mathrm{NO}_{3}^{-}$and $\mathrm{I}^{-}$didn't produce interfering product with NDTT, $\mathrm{NaOH}$ or tartaric acid. 
$\mathrm{Fe}^{2+}, \mathrm{Ba}^{2+}, \mathrm{Mg}^{2+}, \mathrm{Ca}^{2+}, \mathrm{Cd}^{2+}, \mathrm{Co}^{2+}$ and $\mathrm{Sr}^{2+}$ didn't give interfering complexes with NDTT. They were precipitated by addition of $\mathrm{NaOH}$ that had physical interferences. Excess amount of tartaric acid could prevent this precipitation. $\mathrm{Al}^{3+}$ and $\mathrm{Pb}^{2+}$ formed white precipitations with $\mathrm{NaOH}$ which were soluble in excess $\mathrm{NaOH} . \mathrm{Hg}^{2+}$ and $\mathrm{Pd}^{2+}$ formed colored complexes with NDTT. According to the above considerations, the interference from the metal ions should not be significant except that for $\mathrm{Hg}^{2+}$ and $\mathrm{Pd}^{2+}$.

\section{Application of the developed method}

The proposed method has been applied to the determination of copper and nickel in 4 artificial samples and also applied to constantan alloy which contains $45 \%$ of $\mathrm{Ni}^{2+}$ and $55 \%$ of $\mathrm{Cu}^{2+}$. As tables 4 and 5 shows, the values for both the artificial samples and Constantan alloy are identical to the expected amounts and the RSD values lower than 1.15 for the artificial samples and 2.38 for the Constantan alloy and the error lower than 1.3 for all, are acceptable.

Table 4. Determination of nickel $(9,7 \mu \mathrm{g} / \mathrm{mL})$ in presence of copper $(6 \mu \mathrm{g} / \mathrm{mL})$ and copper $(4,8 \mu \mathrm{g} / \mathrm{mL})$ in presence of nickel $(7 \mu \mathrm{g} / \mathrm{mL})$, in artificial samples $(\mathrm{n}=4)$

\begin{tabular}{ccccc}
\hline & Added, $\mu \mathrm{g} / \mathrm{mL}$ & Calculated, $\mu \mathrm{g} / \mathrm{mL}$ & $\mathrm{CV}, \%$ & Error, \% \\
\hline \multirow{2}{*}{$\mathrm{Cu}$} & 4 & $3.98 \pm 0.016$ & 0.41 & -0.6 \\
& 8 & $8.01 \pm 0.065$ & 0.81 & 0.13 \\
\multirow{2}{*}{$\mathrm{Ni}$} & 7 & $6.99 \pm 0.062$ & 0.90 & -0.13 \\
& 9 & $9.05 \pm 0.11$ & 1.15 & 0.56 \\
\hline
\end{tabular}

Table 5. Determination of nickel and copper in Constantan alloy $(\mathrm{n}=10)$

\begin{tabular}{ccc}
\hline $\begin{array}{c}\text { Composition of Constantan alloy } \\
\mathrm{Ni}(45 \%), \mathrm{Cu}(55 \%)\end{array}$ & $\mathrm{Ni}^{2+}$ & $\mathrm{Cu}^{2+}$ \\
\hline Content, $\mu \mathrm{g} / \mathrm{mL}$ & 5.4 & 6.6 \\
Found, $\mu \mathrm{g} / \mathrm{mL}$ & $5.33 \pm 0.13$ & $6.68 \pm 0.15$ \\
$\mathrm{CV}, \%$ & 2.38 & 2.2 \\
Error, $\%$ & -1.3 & 1.3
\end{tabular}

The obtained results confirm that the spectrophotometric method presented in this paper, was successfully applied for $\mathrm{Cu}^{2+}$ and $\mathrm{Ni}^{2+}$ determination in real samples

\section{Conclusion}

From the results of this study it can be concluded that the proposed third-derivative spectrophotometric method for simultaneous determination of copper and nickel using NDTT reagent is a simple, rapid, practical, reliable and inexpensive method. The extracted red colored Cu-NDTT and yellow colored Ni-NDTT complexes make the method very selective as well. Analysis of alloy sample showed that this method can be successfully used for simultaneous determination of $\mathrm{Cu}$ and $\mathrm{Ni}$ in real samples. So the recommended method can be easily and rapidly used in routine analysis.

\section{References}

1. Fakhari A R, Khorrami A and Naeimi H, Talanta, 2005, 66(4), 813-817.

2. Ghaedi M, Spectrochim Acta A: Mol Biomol Spectrosc., 2007, 66(2), 295-301.

3. Chmilenko F A, Mikulenko O V, Chmilenko T S and Matorina E V, J Water Chem Technol., 2007, 29(3), 139-143.

4. Eskandari H and Kamali Y, Anal Sci., 2004, 20(7), 1095-1098. 
5. Di J, Wu Y and Ma Y, Spectrochim Acta A: Mol Biomol Spectrosc., 2005, 61(5), 937-941.

6. Subramanyam Sarma L, Rajesh Kumar J, Janardhan Reddy K and Varada Reddy A, $J$ Agric Food Chem., 2005, 53(14), 5492-5498.

7. Haver T C, Anal Proc., 1982, 19, 22.

8. Rote A R and Bari1 P D, AAPS Pharm Sci Tech, 2009; DOI: 10.1208/s12249-0099318-y

9. El-Yazbi, Fawzy A, Hammud Hassan H and Sonji Ghassan M, Int J Appl Chem., 2007, 3, 1-12.

10. Niazi A and Yazdanipour A, Chin Chem Lett., 2008, 19(7), 860-864.

11. Varghese A, Khadar A M A and Kalluraya B, Spectrochim Acta A: Mol Biomol Spectrosc., 2006, 64(2), 383-390.

12. Shamsa F and Barazandeh-Tehrani M, DARU, 2004, 12(2), 76-80.

13. Barazandeh Tehrani, M, Shamsa F, Shams S and Mastari Farahani M, Asian J Chem., 2010, 22(1), 21-26.

14. Souri E, Amanlou M, Farsam H and Afshari A, Chem Pharm Bull., 2006, 54(1), 119-122.

15. Hashem E Y, Spectrochim Acta A: Mol Biomol Spectrosc., 2002, 58(7), 1401-10.

16. Safavi A, Abdollahi H and Mirzajani R, Spectrochim Acta A: Mol Biomol Spectrosc., 2006, 63, 196-199. 


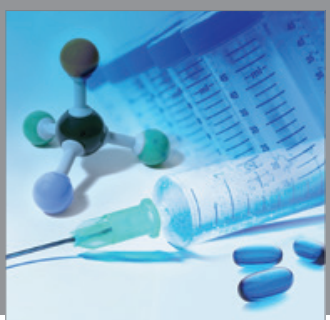

International Journal of

Medicinal Chemistry

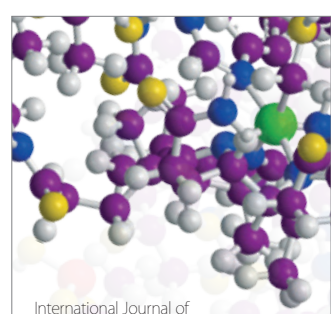

Carbohydrate Chemistry

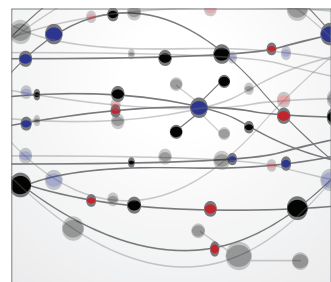

The Scientific World Journal
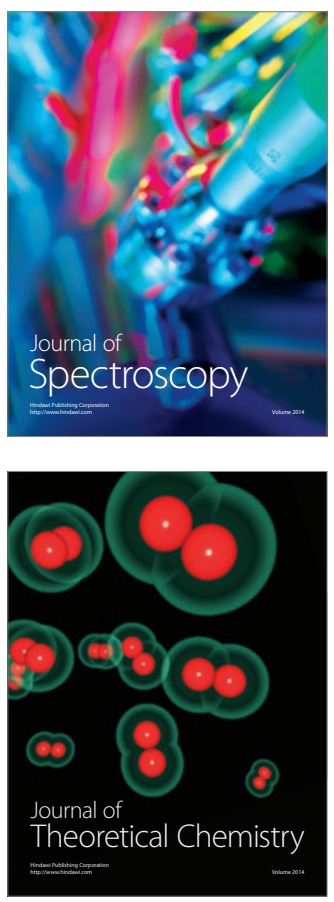
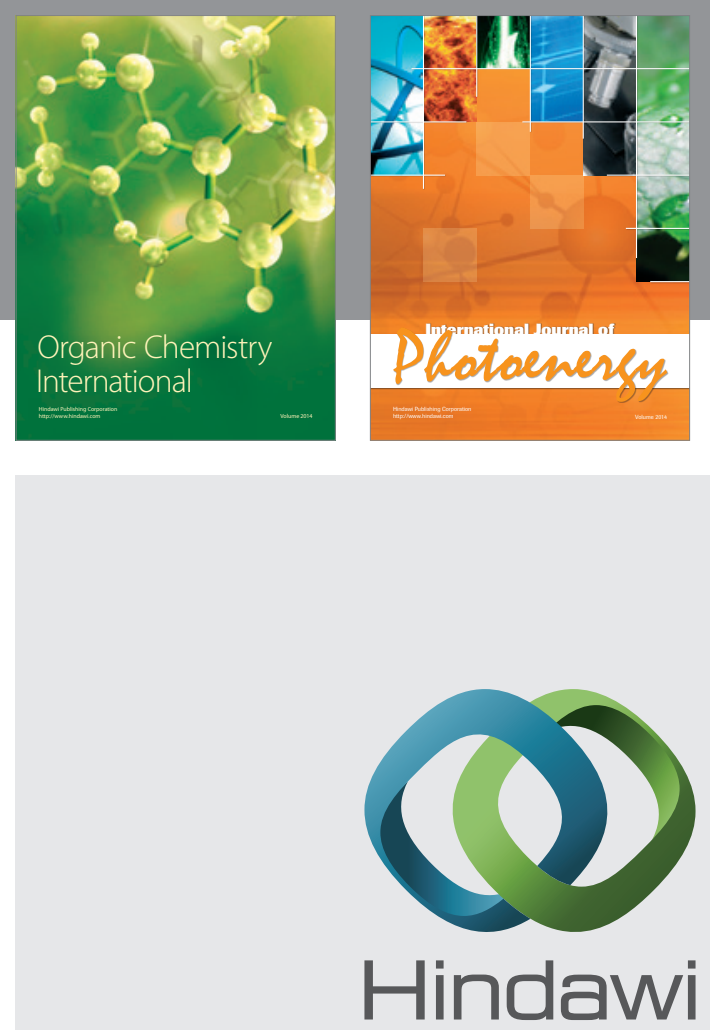

Submit your manuscripts at

http://www.hindawi.com
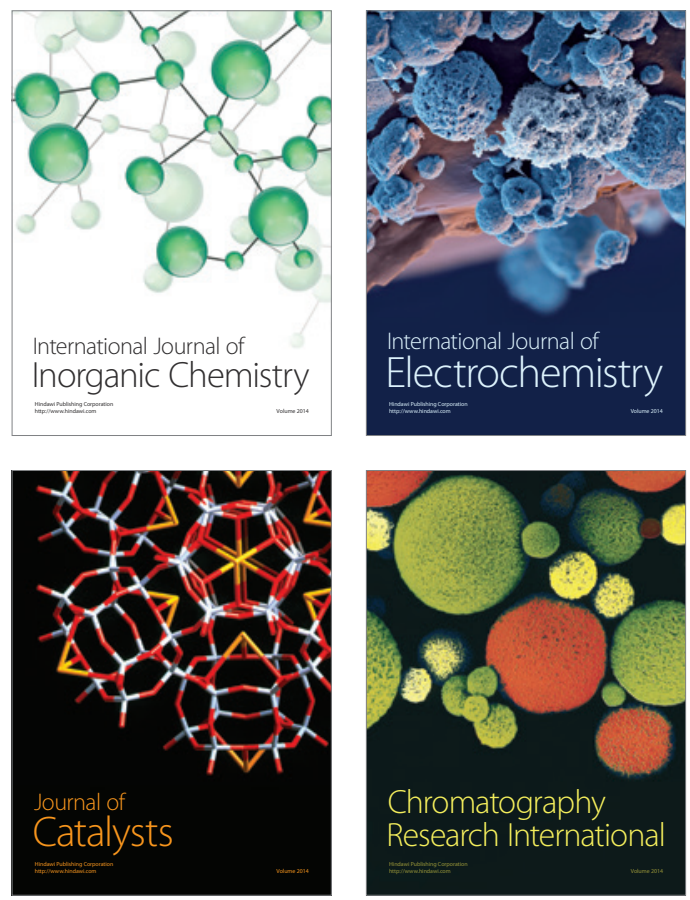
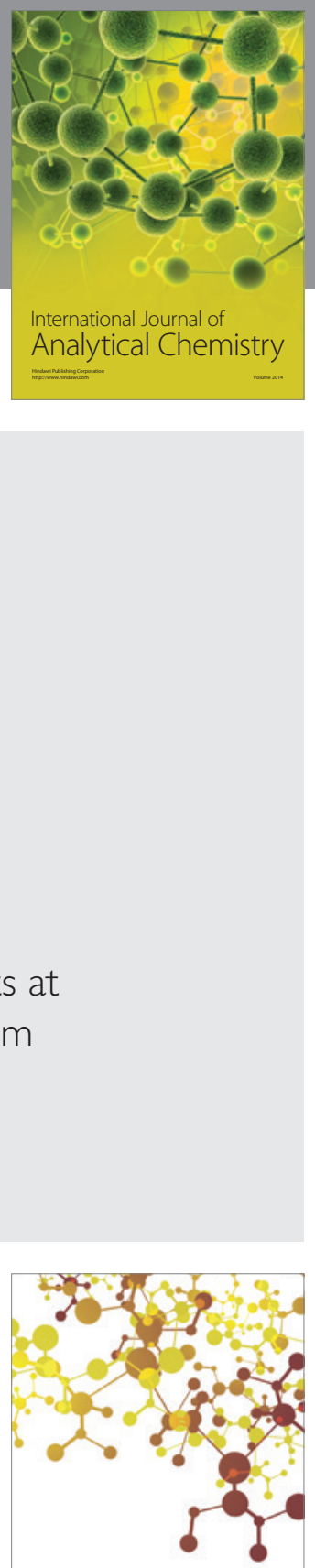

Journal of

Applied Chemistry
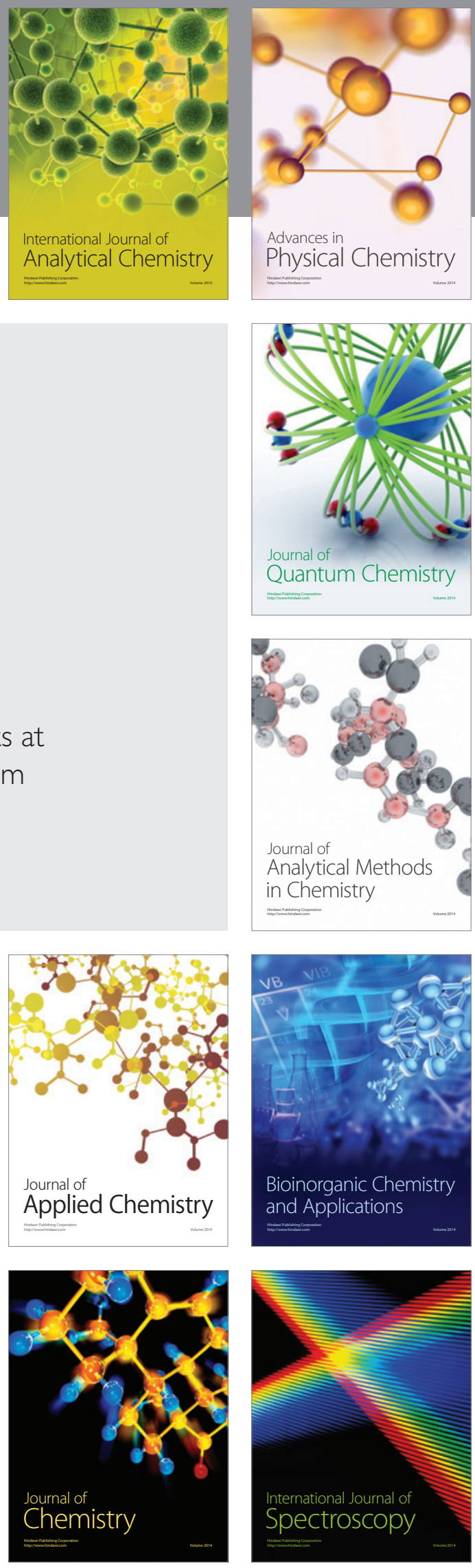